\title{
Multiple site electromyography recordings of uterine activity following an intrauterine bacterial challenge in mares susceptible and resistant to chronic uterine infection
}

\author{
M. H. T. Troedsson ${ }^{1}$, I. K. M. Liu ${ }^{1}$, M. Ing ${ }^{1}$, J. Pascoe ${ }^{2}$ and \\ M. Thurmond ${ }^{3}$ \\ ${ }^{1}$ Department of Reproduction, ${ }^{2}$ Department of Surgery and ${ }^{3}$ Department of Epidemiology and \\ Preventive Medicine, School of Veterinary Medicine, University of California, Davis, CA 95616, \\ USA
}

The electrical myometrial activity of three mares with a documented increased susceptibility to chronic uterine infection (CUI) and three mares considered to be resistant to CUI was investigated. Electrodes were surgically implanted in the myometrium of the mares and electrical activity was monitored by a Grass polygraph. Oestrus was determined by transrectal ultrasonography of the reproductive tract and teasing of the mares with a stallion. Findings were confirmed by blood progesterone concentrations $<0.1 \mathrm{ng} \mathrm{ml}^{-1}$. At the third day of oestrus or when a follicle $>35 \mathrm{~mm}$ was detected, the uterus was infused with a genital strain of $5 \times 10^{6}$ Streptococcus zooepidemicus. Myometrial electrical activity was monitored for $1-4 \mathrm{~h}$ before the bacterial infusion and continued until a visual stabilization of the activity occurred. No statistically significant differences in electrical myometrial activity were detected between susceptible and resistant mares before the infusion of bacteria into the uterus. A visible increase in myometrial electrical activity was seen in all mares following the bacterial infusion. However, the myometrial response of susceptible and resistant mares was different. Resistant mares demonstrated a greater myometrial activity $(P<0.001)$ than did susceptible mares. These differences were observed in frequency $(P<0.005)$ as well as duration $(P<0.001)$ and intensity $(P<0.001)$ of the uterine activity. Differences were most marked between 10 and $20 \mathrm{~h}$ after the intrauterine inoculation of bacteria. It was concluded from this study that myometrial activity is an important part of the uterine defence mechanism in mares. Mares susceptible to CUI appear to have an impaired electrical myometrial activity in response to an intrauterine bacterial challenge.

\section{Introduction}

Chronic uterine infection (CUI) is a common cause of infertility and subfertility in mares. At the time of breeding, the uterus is frequently contaminated with bacteria (Dimmock, 1939; Kenney and Ganjam, 1975). Most young mares can eliminate this infection within $96 \mathrm{~h}$ and have been found to be free from infection at the time when the embryo descends into the uterus (Hughes and Loy, 1969). The mechanisms for resistance against a persistant uterine infection is believed to be the combined result of a cellular phagocytic elimination of bacteria (Asbury et al., 1982; Cheung et al., 1985; Liu et al., 1985, 1986; Asbury and Hansen, 1987; Watson et al., 1987a; Troedsson et al., 1990), a local uterine antibody-mediated immunity (Kenney and Khaleel, 1975; Asbury et al., 1980; Mitchell et al., 1982; Williamson $e$ al., 1983; Widders $e$ al., 1984, 1985) and a physical clearance of bacteria and inflammatory products (Evans et al., 1986; Troedsson and Liu, 1991a). In contrast to young fertile

Received 24 August 1992. mares, older multiparous mares often cannot clear uterine contamination and this can result in a chronic uterine infection (Peterson et al., 1969).

Several workers have investigated at what level compromise in uterine defence occurs in mares susceptible to CUI. It has been shown that the concentration of antibodies within the uterine lumen is the same or even enhanced in susceptible compared with resistant mares (Asbury et al., 1980; Mitchell et al., 1982). It has been suggested that phagocytosis of polymorphonuclear neutrophils (PMN) is dysfunctional in mares that are susceptible to CUI (Cheung et al., 1985; Liu et al., 1985; Watson et al, 1987b). However, in a recent study it was demonstrated that both chemotactic properties of uterine secretion and the ability of uterine PMNs to respond to phagocytosis and chemotaxis were fully functional. An impaired opsonizing function of uterine secretion was, however, found in susceptible mares (Troedsson and Liu, 1991b). It was suggested that this dysfunction is the result of an accumulation of detrimental inflammatory products within the uterus as a result of persistent infections. Older mares and susceptible mares have been found 
to accumulate uterine fluid (Allen and Pycock, 1988; LeBlanc $e t$ al., 1989; Troedsson and Liu, 1992) and to have a dysfunctional mechanical clearance of products from the uterus following an infection (Evans et al, 1987; Troedsson and Liu, 1991a). However, the exact mechanism for this inability to physically clear products from the uterus has not been addressed.

We hypothesized that mares susceptible to CUI have impaired myometrial activity, resulting in persistence of infection and an accumulation of inflammatory products in the uterus following contamination. The objective of this experiment was to study electrical myometrial activity in response to a bacterial challenge in mares susceptible to versus those resistant to CUI. Myometrial activity was monitored, using electromyography (EMG), both before and after the infusion of bacteria into the uterus.

\section{Materials and Methods}

\section{Mares}

Six cyclic mares were used in this study. Mares that were considered to be resistant to CUI $(n=3)$ ranged in age from 3 to 5 years of age. They had no history of reproductive problems and had no significant histopathological findings in uterine biopsies. In addition, resistant mares proved to be capable of completely clearing an induced uterine infection of $5 \times 10^{6}$ Streptococcus zooepidemicus within $\mathbf{4}$ days of the inoculation. All resistant mares had negative uterine cultures and no inflammatory cells on endometrial cytology at this time. Mares classified as susceptible to CUI $(n=3)$ ranged from 15 to 20 years of age. They had a history of CUI with associated fertility problems and had severe inflammatory changes and periglandular fibrosis in uterine biopsies (Kenney, 1978). Susceptibility to CUI was confirmed by a bacterial uterine challenge. Only mares that had positive cytology and uterine cultures four days after the inoculation of Streptococcus zooepidemicus were classified as susceptible.

\section{Implantation of myometrial electrodes}

Six pairs of bipolar electrodes were surgically implanted into the myometrium. The uterus was exposed via a midventral laparotomy performed under general anaesthesia induced by $100 \mathrm{mg}$ guaifenesin $\mathrm{kg}^{-1}$ (Rhone-Poulene, Collegeville, PA) and $2 \mathrm{mg}$ thiamylal $\mathrm{kg}^{-1}$ (Surital; Parke Davis, Morris Plains, NJ) i.v. and maintained with halothane (Halocarbon Laboratories, N. Augusta, SC). Four pairs of sterile electrodes (44-gauge multistrand stainless steel Teflon-coated wire) were implanted into the myometrium, spread $3-5 \mathrm{~cm}$ apart at the tip of the left horn, the middle of the left horn, the base of the left horn and the uterine body. Similarly, two pairs of electrodes were implanted in the middle and base of the right horn. A loop was made in each wire $5 \mathrm{~cm}$ from the distal end of the electrodes. The Teflon was stripped from the electrodes over a $10 \mathrm{~mm}$ long segment just distal to the loop. The electrodes were implanted into the myometrium, using a tapered needle, and secured via a suture (prolene 3-0) through the loop. Electrodes within a pair were implanted $1 \mathrm{~cm}$ apart. The most distal ends of the electrodes were cut, leaving the stripped area embedded into the myometrium. This technique allowed exposure of the electrodes to both the longitudinal and circular layers of the myometrium. The recorded activity therefore represented the combined activity of the two myometrial layers. Each electrode, covered by a Teflon tube, was passed through the abdominal wall of the left flank, tunnelled subcutaneously, exteriorized near the withers, fixed in place and capped.

\section{EMG recordings}

After implantation and recovery from surgery, the mares were allowed to rest for at least one week for the uterus to stabilize. Electrical activity (EMG) was monitored by a Grass polygraph. EMG signals were amplified through Grass DC preamplifiers and the signals were transcribed to a Grass polygraph at a chart speed of $10 \mathrm{~mm} \mathrm{~min}^{-1}$ and at an amplitude of $50 \mu \mathrm{V} \mathrm{cm}{ }^{-1}$. Signal filters were set at 10 and $35 \mathrm{~Hz}$ (Haluska et al., 1987).

The mares were fed alfalfa hay and kept in stalls during the entire experiment. Oestrous behaviour was detected by daily teasing with a stallion. Transrectal ultrasonography of the reproductive tract was performed when the mares showed signs of oestrus. Oestrus was confirmed by concentrations of progesterone in blood $<1.0 \mathrm{ng} \mathrm{ml}^{-1}$ in the presence of a follicle $>35 \mathrm{~mm}$.

\section{Collection of blood samples}

In conjunction with each recording session, $20 \mathrm{ml}$ of venous blood was withdrawn from the jugular vein into a vacutainer system (Becton Dickinson, Rutherford, NJ) containing sodium heparin as an anticoagulant. The samples were centrifuged at $400 \mathrm{~g}$ for $10 \mathrm{~min}$ and plasma was removed and stored at $-20^{\circ} \mathrm{C}$ until analysed for progesterone.

\section{Hormone analysis}

Plasma progesterone was analysed using a solid-phase microtitre plate enzymeimmunoassay as described by Munro and Stabenfeldt (1984). Progesterone 3-O-carboxymethyloximehorseradish peroxidase was used as the label and the antiserum was raised in rabbits against a progesterone $11 \alpha$-hemisuccinylBSA immunogen. Progesterone 3-O-carboxymethyloxime and $11 \alpha$-hemisuccinate-BSA were purchased from Steraloids, Inc. (Wilton, NH). Horseradish peroxidase was obtained from Sigma Chemical Co. (St Louis, MO). The mean intra-assay coefficient of variation was $9.97 \%$ and the average interassay coefficients of variation for pools of high, medium and low progesterone concentration were $4.9,6.2$ and $10.5 \%$, respectively. The sensitivity of the progesterone assay was $<0.1 \mathrm{ng} \mathrm{ml}^{-1}$.

\section{Infections}

Before each experiment, the mares were confirmed to be free from infection as determined by endometrial culture and cytology. At the third day of oestrus or when a $35 \mathrm{~mm}$ follicle was detected, the mares were infected with a genital strain of $5 \times 10^{6}$ Streptococcus zooepidemicus. The perineal region was aseptically prepared with extra precaution taken to cleanse 
the clitoral fossa. The bacterial culture suspended in $30 \mathrm{ml}$ phosphate-buffered saline solution (PBS) was infused from an insemination pipette into the uterus. As a negative control, each mare was infused with PBS alone in a subsequent oestrous period.

Uterine activity was monitored for $1-4 \mathrm{~h}$ before the infusion of $5 \times 10^{6}$ Streptococcus zooepidemicus or PBS (negative control) into the uterus and was continued until visual stabilization of the activity occurred. At the end of each recording, $20 \mathrm{iu}$ of oxytocin was given i.v. to serve as a control for myometrial activity.

\section{$E M G$ analyses}

All recordings were manually transformed to a digitized form and voltage activity was measured in three ways (Troedsson $e$ t al., 1993). (1) Frequency was defined as the number of activity bursts per hour, with each burst consisting of at least ten spikes per minute and separated from other bursts by at least one minute. (2) Duration was defined as the time ( $\mathrm{min}$ ) that elapsed from the start to the end of a burst. (3) Intensity was measured as the number of spikes per minute. Intensity was coded as low

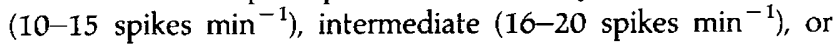
high ( $>20$ spikes $\min ^{-1}$ ). Additionally, all activity recorded (regardless of intensity) was classified as total activity and was expressed as the percentage of time any activity was recorded.

In addition, the presence or absence of synchronous activity was expressed as the number of myometrial implantation sites which were active simultaneously and the number which were quiescent simultaneously. Complete synchronous activity occurred when there was simultaneous activity or quiescence at all locations.

\section{Statistical analyses}

The mean of the recorded uterine myometrial activity before the infection was tested for significant differences regarding frequency, duration, intensity and total uterine activity between susceptible and resistant mares using a Student's $t$ test. Analysis of variance and covariance with repeated measures were used to compare uterine activity following infection over time between susceptible and resistant mares. Differences in frequency, duration, intensity and synchronization were compared separately. Because of technical problems with the two pairs of electrodes implanted in the right horn of two mares, data from the right horn was excluded from all mares and analyses were made only from the four pairs of electrodes in the left horn and uterine body. Comparisons were not made for each time point owing to the small sample size, but inferences were made from the regularity of the pattern of recordings obtained.

The results were expressed as means \pm SEM. Significance was set at $P<0.05$.

\section{Results}

An increase in myometrial electrical activity was seen in all mares after they were infected with Streptococcus zooepidemicus. Infusion of PBS into the uterus did not affect uterine activity, with the exception of an immediate increase of frequency and synchrony that lasted for only 10-15 min.

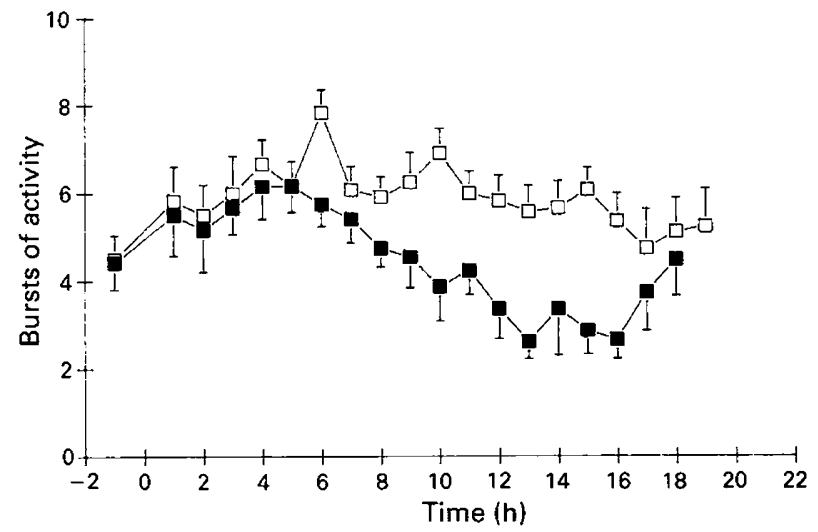

Fig. 1. The number of activity bursts per hour following an induced intrauterine challenge in mares $(\square)$ susceptible versus $(\square)$ resistant to chronic uterine infection. Both groups show an initial increase in activity. Activity bursts subsequently decline to below resting values in the susceptible mares up to $16 \mathrm{~h}$ after infection.

A vaginal discharge was observed in all mares, starting approximately $5 \mathrm{~h}$ after infection. In the resistant mares, the discharge disappeared after $20 \mathrm{~h}$, whereas in the susceptible mares a purulent vaginal discharge was still visible at the end of the experiment.

\section{Frequency}

No differences in the frequency of uterine electrical activity were detected between susceptible $(4.42 \pm 0.61$ bursts of activity $\left.\mathrm{h}^{-1}\right)$ and resistant mares $(4.50 \pm 0.55$ bursts of activity $\left.\mathrm{h}^{-1}\right)$ in the absence of a uterine infection $(P>0.05)$. However, in both resistant and susceptible mares the frequency of uterine activity for the first $5 \mathrm{~h}$ of infection was greater than before infection (Fig. 1). From 5 to $17 \mathrm{~h}$ after the infection, significant differences between susceptible and resistant mares were observed $(P<0.001)$. The increased frequency was sustained during this time in the resistant group until $18 \mathrm{~h}$ after infection, when a slow decline to preinfection values occurred. In contrast, the susceptible group showed a marked decline in frequency between 7 and $17 \mathrm{~h}$ after infection to values below that seen before infection. After $17 \mathrm{~h}$ of infection, the frequency increased to preinfection values in susceptible mares.

\section{Duration}

No differences in the duration of the activity burst were found between susceptible and resistant mares before infection $(3.93 \pm 0.63 \mathrm{~min}$ versus $4.24 \pm 0.56 \mathrm{~min} ; P>0.05)$. Differences between the groups of mares were observed between 12 and $18 \mathrm{~h}$ after the infection (Fig. 2). The activity bursts were longer in the resistant mares than in the susceptible mares during this period $(P<0.001)$.

\section{Intensity}

No differences were detected in the intensity of uterine activity before infection between susceptible and resistant 


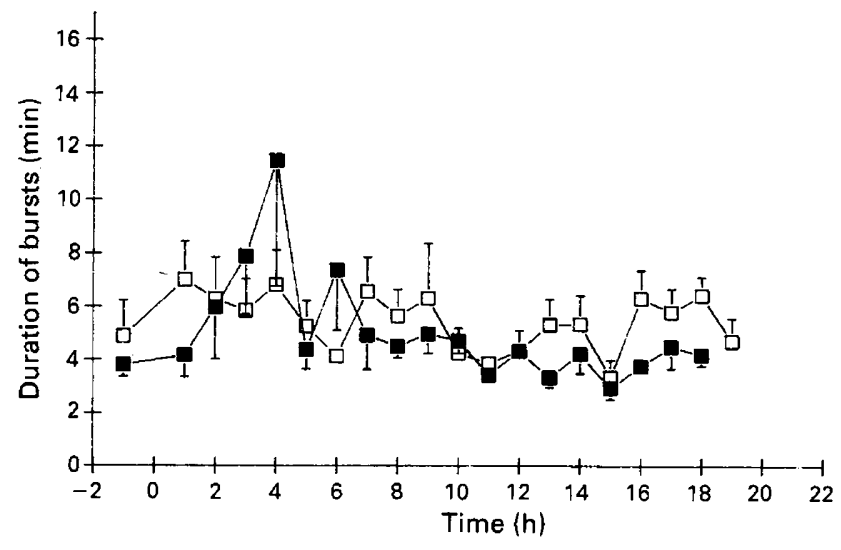

Fig. 2. The duration of uterine electrical activity bursts following an induced intrauterine bacterial challenge in mares $(\boldsymbol{D})$ susceptible and $(\square)$ resistant to chronic uterine infection.

mares. Low intensity activity was seen for $7.11 \pm 0.97 \mathrm{~min}^{-1}$ in the susceptible mares and $7.8 \pm 0.78 \mathrm{~min} \mathrm{~h}^{-1}$ in the resistant mares $(P>0.05)$. Intermediate intensity was observed for $4.50 \pm 0.80 \mathrm{~min} \mathrm{~h}^{-1}$ in the susceptible group and $5.73 \pm$ $0.94 \mathrm{~min} \mathrm{~h}^{-1}$ in the resistant group $(P>0.05)$. The susceptible mares had a high intensity of uterine activity for $6.54 \pm 1.23$ $\operatorname{min~} \mathrm{h}^{-1}$, compared with $9.18 \pm 0.91 \mathrm{~min}^{-1}$ for the resistant mares $(P>0.05)$.

A statistically significant difference was detected between susceptible and resistant mares for all levels of intensity of uterine electrical activity $(P<0.001)$ (Fig. 3). Differences in low intensity activity between the groups were observed $13 \mathrm{~h}$ after the infection and lasted throughout the remainder of the experiment. At this time, low intensity activity was more frequent among the resistant than the susceptible mares.

Uterine activity of intermediate intensity declined over time in the susceptible group. Intermediate intensity activity occurred more frequently in the resistant mares than in the susceptible mares $(P<0.001)$. This was particularly obvious at $12 \mathrm{~h}$ after infection and beyond.

High intensity uterine activity was observed more often in the resistant than in the susceptible group of mares following infection $(P<0.001)$. In both susceptible and resistant mares, an increase of high intensity activity was seen during the first $9 \mathrm{~h}$ of infection. The increase of high intensity activity was delayed by $2 \mathrm{~h}$ in the susceptible mares compared with the resistant group. In susceptible mares, a decline below preinfection values occurred $9 \mathrm{~h}$ after infection. This was not observed in the resistant group.

The total uterine activity following an infection also demonstrated different patterns over time between susceptible and resistant mares $(P<0.001)$. The activity increased in both groups of mares during the first $6 \mathrm{~h}$ after the infection (Fig. 4). However, the onset of activity was delayed and was followed by a sharp decline in activity in the susceptible group. After $11 \mathrm{~h}$ and continuing until the end of the experiment (18 h), only a very low uterine activity was present in susceptible mares. In contrast, the resistant mares showed increased uterine activity for a longer period with only temporary decreases in activity occurring at 11,15 and $19 \mathrm{~h}$ after inoculation.
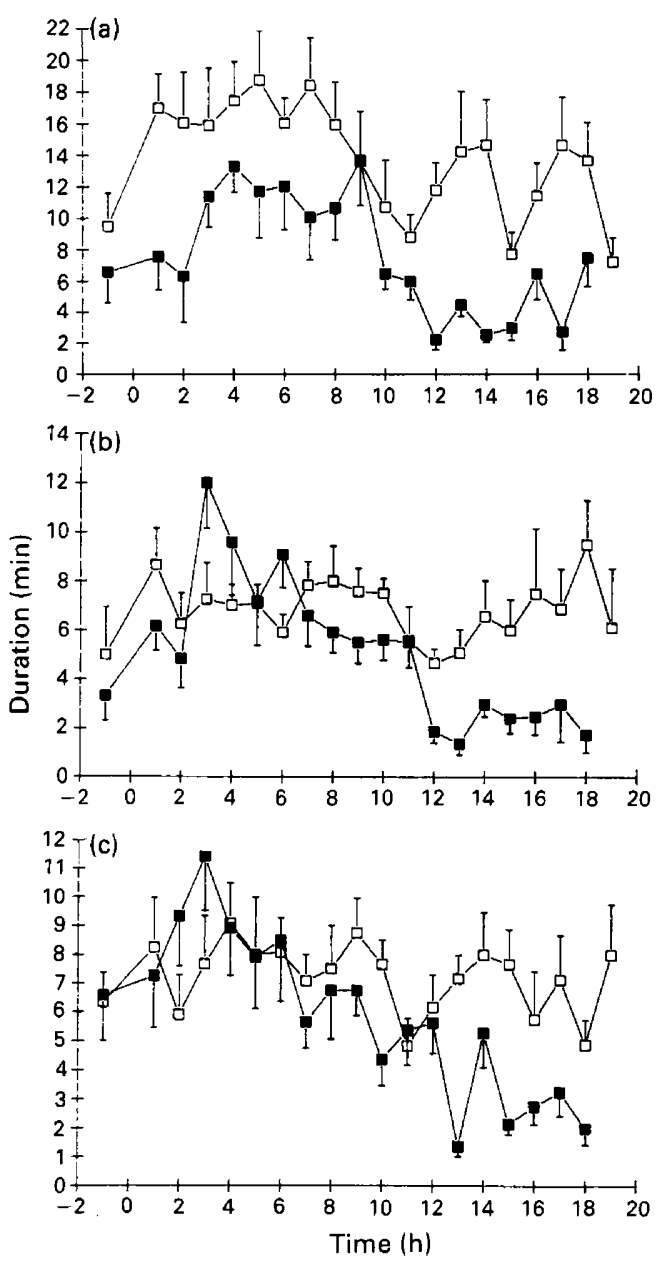

Fig. 3. (a) High, (b) medium and (c) low intensity of uterine electrical activity following an intrauterine bacterial challenge in mares $(\square)$ susceptible and $(\square)$ resistant to chronic uterine infection. Resistant mares had significantly $(P<0.001)$ more high intensity uterine activity than did susceptible mares. All levels of intensity progressively declined 6-8 $\mathrm{h}$ after infection in susceptible mares.

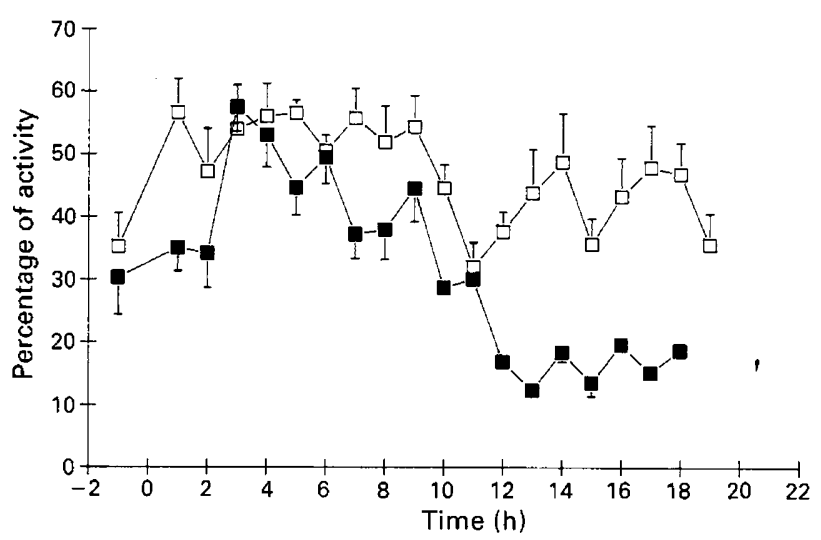

Fig. 4. Total uterine electrical activity following an intrauterine bacterial challenge in mares $(\square)$ susceptible and $(\square)$ resistant to chronic uterine infection. Resistant mares showed more total uterine activity than did susceptible mares. After an initial increase, total uterine activity progressively declined in the susceptible mares. 


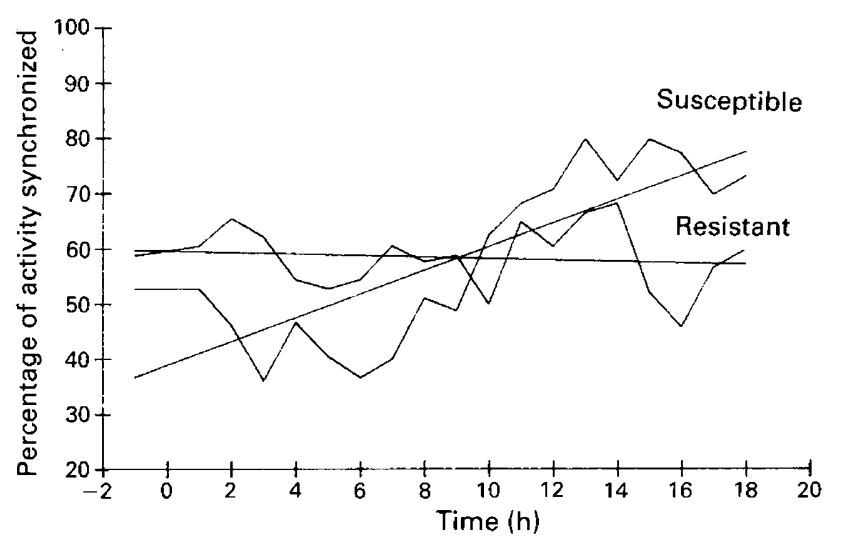

Fig. 5. The percentage of synchronized electrical uterine activity following an intrauterine bacterial challenge in mares susceptible and resistant to chronic uterine infection. The estimated regression lines show that while synchronization does not change in the resistant mares, an increase over time occurs in the susceptible mares.

\section{Synchronization}

In the absence of an infection among the susceptible mares, asynchrony of uterine electrical activity between any of the four implantation sites occurred for $38.84 \pm 5.1 \%$ of the time. This was not statistically different from that of the resistant mares (46.81 $\pm 4.05 \% ; P>0.05$ ).

Although synchronization of uterine activity in the resistant group was relatively constant throughout the experiment, synchronization occurred with increasing frequency in the susceptible group for $8-10 \mathrm{~h}$ after infection $(P<0.03)$ (Fig. 5 ).

\section{Discussion}

Electromyographic recordings of myometrial activity have been performed in several species (Zerobin and Spörri, 1972; Naaktgeboren et al., 1973; Taverne et al., 1979a; Krishnamurti et al., 1982; Thorburn et al., 1984; Toutaine et al., 1983; Faltsi and Brikas, 1990). In mares, myometrial activity has been found to change during different stages of the oestrous cycle (Taverne et al., 1979b; Troedsson et al., 1993). Shorter duration of activity bursts is found during oestrus than during dioestrus. In addition, the intensity as well as synchronization between different parts of the uterus are greater during oestrus.

The functional importance of a more pronounced activity of the myometrium during oestrus has not been established. Cervical-uterine-oviductal activity may be necessary for the transport of spermatozoa. In addition, uterocervical myometrial activity may protect the uterus from invading microorganisms by continually moving endometrial gland secretions through an open cervix. Neither the directions of contractions, nor the direction of the movement of intraluminal fluids were investigated in this study. However, the observed vaginal discharge in all mares and the previously noted ability of the uterus to transport microspheres through the cervix following an infection (Troedsson and Liu, 1991a) indicates that the uterine activity measured in the present study corresponded to uterocervical removal of inflammatory products from the uterus. Monitoring of intrauterine pressure in combination with EMG may better describe movement of intrauterine fluids. However, the presence of instruments in the uterine lumen has the disadvantage that contact with the endometrium is likely to induce mechanical irritation, which may trigger both contractile and inflammatory responses.

Physical uterine defence mechanisms, including the ability to clear inflammatory products following uterine contamination, are believed to be essential for resistance to persistant uterine infection (Evans et al., 1987; Boyd and Allen, 1987; Troedsson and Liu, 1991a). The present study confirms the importance of uterine activity as a component of physical uterine defences. All mares responded to an intrauterine bacterial challenge with a marked increase in myometrial activity. The enhanced uterine activity lasted for up to $20 \mathrm{~h}$. This corresponded well to a previous observation that radioactively labelled non-antigenic microspheres were almost completely eliminated from the uterus within $24 \mathrm{~h}$ after infection (Troedsson and Liu, 1991a).

The mechanism that produces increased myometrial activity during uterine infection is not known. A rapid migration of activated $P M N$ and high concentrations of prostaglandins PGF $_{2 \alpha}$ and PGE) have been demonstrated in conjunction with acute uterine infection (Watson et al., 1987a; Pycock and Allen, 1988). Receptors for prostaglandins have been identified in the myometrium and prostaglandin release is believed to increase myometrial activity via an activation of the phosphoinositol cycle and an increase in intracellular $\mathrm{Ca}^{2+}$ (Carsten and Miller, 1981, 1990). It seems likely, therefore, that prostaglandins, released from activated PMNs, may be responsible for increased myometrial activity during infection.

In addition to identifying enhanced myometrial activity as a response to intrauterine infection, the study reported here shows that there are marked differences in myometrial activity following an infection between mares susceptible to and resistant to chronic uterine infection. A previous study showed that the physical capacity of the uterus to clear non-inflammatory markers was reduced in mares susceptible to compared with mares resistant to CUI (Troedsson and Lui, 1991a). The present study shows that the mechanism behind this may be a dysfunctional myometrial activity during infection. In the absence of inflammation, uterine electrical activity did not differ between susceptible and resistant mares under the conditions of this experiment. However, major differences were demonstrated in association with an intra-uterine bacterial challenge. All mares showed an initial increase in myometrial activity; however, the increase in uterine activity (as measured by number of activity bursts per hour), the duration of the activity bursts, the total activity and the intensity declined rapidly in the susceptible group. Susceptible mares also had poorer synchronization of activity as well as less high intensity activity during the early stages of inflammation compared with resistant mares. The majority of the observed differences between susceptible and resistant mares occurred $12 \mathrm{~h}$ or more after the mares were infected. The decline in activity cannot be explained by a decline in inflammatory stimulation of the myometrium because, by definition, all mares susceptible to CUI had a persistent uterine infection $96 \mathrm{~h}$ after infection. In addition, a purulent vaginal discharge was observed in all susceptible mares at the end of the experiment. It is more likely that a shorter and weaker myometrial response is, at least in part, responsible for the delayed 
physical clearance of inflammatory products from the uterus. As no differences were detected in myometrial activity in the absence of an infection, further studies of the ultrastructure and biochemistry of the myometrium following an infection are needed to determine the cause of this dysfunction.

In conclusion, this study shows that myometrial activity is an important part of the physical uterine defence mechanism in mares. Furthermore, mares that are susceptible to chronic uterine infection appear to have an impaired electrical myometrial activity in response to an intrauterine bacterial challenge.

This project was supported by the Equine Research Laboratory, University of California, Davis, with funds provided by the Oak Tree Racing Association, the State of California satellite wagering fund and contributions from private donors. The authors would also like to acknowledge the financial support of the Swedish Racing Board (ATG). We thank C. Munro for performing hormonal analyses, G. Haluska for his insights and for providing us with electrodes and T. Holliday for his insight and help with the manuscript.

\section{References}

Allen WE and Pycock JF (1988) Cyclical accumulation of uterine fluid in mares with lowered resistance to endometritis Veterinary Records 122 489-490

Asbury AC and Hansen PJ (1987) Effects of susceptibility to endometritis and stage of the cycle on phagocytic activity of uterine derived neutrophils Joumal of Reproduction and Fertility Supplement 35 311-316

Asbury AC, Halliwell REV, Foster GW and Longino SJ (1980) Immunoglobulins in uterine secretions of mares with differing resistance to endometritis Theriogenology 14 299-308

Asbury AC, Schultz KT, Klesuis PH, Foster GW and Washburn SM (1982) Factors affecting phagocytosis of bacteria by neutrophils in the mares uterus Journal of Reproduction and Fertility Supplement 32 151-159

Boyd EH and Allen WE (1987) Absorption of neomycin from the equine uterus: effect of stage of oestrous cycle and volume of vehicle Equine Veterinary Journal 19 195-197

Carsten ME and Miller JD (1981) Prostaglandin E, receptor in the myometrium: distribution in subcellular fractions Archives of Biochemistry and Biophysics 212 700-704

Carsten ME and Miller JD (1990) Calcium control mechanisms in the myometrial cell and the role of the phosphoinositide cycle. In Uterine Function, Molecular and Cellular Aspects pp 121-167 Eds ME Carsten and JD Miller. Plenum Press. New York

Cheung ATW, Liu IKM, Walsh EM and Miller ME (1985) Phagocytic and killing capacities of uterine derived polymorphonuclear leukocytes from mares resistant and susceptible to chronic endometritis American Joumal of Veterinary Research 46 1938-1940

Dimmock WW (1939) Equine breeding hygiene Joumal of American Veterinary Medical Association 94 469-478

Evans MJ, Hamer JM, Gason LM, Graham CS, Asbury AC and Irwine CHG (1986) Clearance of bacteria and non-antigen markers following intra-uterine inoculation into maiden mares: effect of steroid hormone environment Theriogenology 26 37-50

Evans MJ, Hamer JM, Gason LM and Irwine CHG (1987) Factors affecting uterine clearance of inoculated materials Journal of Reproduction and Fertility Supplement 35 327-334

Faltsi A and Brikas P (1990) An electromyographic study of uterine activity during normal and progesterone-regulated oestrus in the ewe Theriogenology 34 603-611

Haluska GJ, Lowe JE and Currie WB (1987) Electromyographic properties of the myometrium correlated with endocrinology of the pre-partum and postpartum periods and parturition in pony mares Journal of Reproduction and Fertility Supplement 35 553-564

Hughes JP and Loy RG (1969) Investigations on the effect of intrauterine inoculation of Streptococcus zooepidemicus in the mare. In Proceedings of the American Association of Equine Practitioners pp 289-292 Ed FJ Milne. AAEP Publications, Lexington
Kenney RM (1978) Cyclic and pathologic changes of the mare endometrium as detected by biopsy, with a note on early embryonic death Joumal of American Veterinary Medical Association 172 241-262

Kenney RM and Ganjam VK (1975) Selected pathological changes of the mare uterus and ovary Journal of Reproduction and Fertility Supplement 23 335-339

Kenney RM and Khaleel SA (1975) Bacteriostatic activity of the mare uterus: a progress report on immunoglobulins Joumal of Reproduction and Fertility Supplement 23 357-358

Krishnamurti CR, Kitts DD, Kitts WD and Tompkins JG (1982) Myoelectrical changes in the uterus of the sheep around parturition Journal of Reproduction and Fertility 64 59-67

LeBlanc MM, Asbury AC and Lyle SK (1989) Uterine clearance mechanisms during the early postovulatory period in mares American Journal of Veterinary Research 6 864-867

Liu IKM, Cheung ATW, Walsh EM, Miller ME and Lindenberg PM (1985) Comparison of peripheral blood and uterine derived polymorphonuclear leukocytes from mares resistant and susceptible to chronic endometritis: chemotactic and cell elastimetry analysis American Journal of Veterinary Research 46 917-920

Liu IKM, Cheung ATW, Walsh EM and Ayin S (1986) The functional competence of uterine derived polymorphonuclear neutrophils (PMN) from mares resistant and susceptible to chronic uterine infection: a sequential migration analysis Biology of Reproduction 35 1168-1174

Mitchell G, Liu IKM, Perryman LE, Stabenfeldt GH and Hughes JP (1982) Preferential production and secretion of immunoglobulins by the equine endometrium - a mucosal immune system Joumal of Reproduction and Fertility Supplement 32 161-168

Munro C and Stabenfeldt G (1984) Development of a microtitre plate enzyme immunoassay for the determination of progesterone Joumal of Endocrinology $10141-49$

Naaktgeboren C, van der Weyden GC, Klopper PJ, Kroon CH, Schoof AG and Taverne MAM (1973) Electrophysiological observations of uterine motility during the oestrous cycle in sheep Journal of Reproduction and Fertility 35 511-518

Peterson FB, McFeely RA and David JSE (1969) Studies on the pathogenesis of endometritis in the mare. In Proceedings of the American Association of Equine Practitioners pp 279-285 Ed FJ Milne. AAEP Publications, Lexington

Pycock JF and Allen WE (1988) Pre-chemotactic and chemotactic properties of uterine fluid from mares with experimentally induced endometritis Veterinary Record 123 193-195

Taverne MAM, Naaktgeboren C, Elsaesser F, Forsling ML, van der Weyden GC, Ellendorff F and Smidt D (1979a) Myometrial electrical activity and plasma concentrations of progesterone, estrogen and oxytocin during late pregnancy and parturition in the miniature pig Biology of Reproduction 21 1125-1134

Taverne MAM, van der Weyden GC, Fontijne P, Dielman SJ, Pashen RL and Allen WR (1979b) In vivo myometrial electrical activity in the cycling mare Joumal of Reproduction and Fertility 56 521-532

Thorburn GD, Harding R, Jenkin G, Parkington H and Sigger JN (1984) Control of uterine activity in the sheep Journal of Developmental Physiology 6 31-43

Toutain PL, Garcia-Villar R, Hanzen C and Ruckebush Y (1983) Electrical and mechanical activity of the cervix in the ewe during pregnancy and parturition Journal of Reproduction and Fertility 68 195-204

Troedsson MHT and Liu IKM (1991a) Uterine clearance of non-antigenic markers $\left({ }^{51} \mathrm{Cr}\right)$ in response to a bacterial challenge in mares potentially susceptible and resistant to chronic uterine infections Joumal of Reproduction and Fertility Supplement 44 283-288

Troedsson MHT and Liu IKM (1991b) Function of uterine derived PMNs in mares susceptible and resistant to chronic uterine infection (CUI): phagocytosis and chemotaxis. In Uterine Defense Mechanisms in the Mare pp 132-169. MHT Troedsson, PhD Thesis, University of California, Davis

Troedsson MHT and Liu IKM (1992) Measurement of total volume and protein concentration of intrauterine fluid following a bacterial challenge in mares with differing resistance to chronic uterine infection American Joumal of Veterinary Research 53 1641-1644

Troedsson MHT, Concha C, Einarsson S and Holmberg O (1990) A preliminary study of uterine derived polymorphonuclear cell function in mares with chronic uterine infections Acta Veterinaria Scandinavica 31 187-192

Troedsson MHT, Wiström AOG, Liu IKM, Ing M and Pascoe J (1993) Registration of myometrial activity, using multiple site electromyography in the cyclic mare Joumal of Reproduction and Fertility 99 299-306

Watson ED, Stokes CR, David JSE and Bourne FJ (1987a) Concentration of uterine luminal prostaglandins in mares with acute and persistent endometritis Equine Veterinary Journal $1931-37$ 
Watson ED, Stokes CR and Bourne FJ (1987b) Cellular and humoral mechanisms in mares susceptible and resistant to persistent endometritis Veterinary Immunology and Immunopathology 16 107-121

Widders PR, Stokes CR, David JSE and Bourne FJ (1984) Quantification of the immunoglobulins in reproductive tract secretions of the mare Research in Veterinary Science 37 324-330

Widders PR, Stokes CR, David JSE and Bourne FI (1985) Specific antibodies in the equine genital tract following systemic and local immunization immunology 54 763-769
Williamson P, Duning A, O'Conner J and Penhale WJ (1983) Immunoglobulin levels, protein concentrations and alkaline phosphatase activity in uterine flushings from mares with endometritis Theriogenology 19 441-448

Zerobin K and Spörri $\mathbf{H}$ (1972) Motility of the bovine and porcine uterus and fallopian tube Advances in Veterinary Science and Comparative Medicine 16 303-354 